\title{
Experimental and Simulation Study on Shielding Performance of Developed Hydrogenous Composites
}

\author{
Minghui Cai $\mathbb{D}^{1,2}{ }^{1,2 a o}$ Yang, ${ }^{1}$ Hongwei Li, ${ }^{1,2}$ Haixia Yang, ${ }^{3}$ and Jianwei Han ${ }^{1,2}$ \\ ${ }^{1}$ National Space Science Center, Chinese Academy of Sciences, Beijing 100190, China \\ ${ }^{2}$ School of Astronomy and Space Science, University of Chinese Academy of Sciences, Beijing 100049, China \\ ${ }^{3}$ Institute of Chemistry, Chinese Academy of Sciences, Beijing 100190, China
}

Correspondence should be addressed to Minghui Cai; caiminghui@nssc.ac.cn

Received 12 August 2021; Accepted 24 November 2021; Published 27 January 2022

Copyright (C) 2022 Minghui Cai et al. Exclusive Licensee Beijing Institute of Technology Press. Distributed under a Creative Commons Attribution License (CC BY 4.0).

\begin{abstract}
Space radiation has been well-known as the main health hazard to crews involved in manned space explorations. Two kinds of hydrogenous-rich composites are developed through compressing molding under high-temperature processing techniques for shielding space radiation. Beams of $80 \sim 400 \mathrm{MeV} / \mathrm{n}{ }^{12} \mathrm{C}$ of the Heavy Ion Research Facility in Lanzhou are used to test the shielding properties of the new composites. Experimental results show that the composite with more hydrogen content has higher shielding ability for 80 and $400 \mathrm{MeV} / \mathrm{n}{ }^{12} \mathrm{C}$ particles. Meanwhile, the addition of boron has no obvious effect on improving the shielding performance of the composite. Monte Carlo radiation transport codes were used to assess the shielding performance of composite in real space radiation. The simulation results show that hydrogenous-rich composite has significant advantage in space radiation shielding compared with traditional aluminum.
\end{abstract}

\section{Introduction}

Space radiation has been identified as the main health hazard to crews involved in long-term interplanetary space missions. In deep space environment, without the protection of the terrestrial magnetic field, Solar Particle Events (SPEs) emitted by the Sun and the much more energetic Galactic Cosmic Rays (GCRs) that originated and accelerated in the galaxy are the two types to be considered. Sometimes, SPEs last for several hours up to a few days with a very high flux of energetic protons, which can lead to acute effects, including lethal radiation syndromes. The energy of the GCRs is much higher, at least of an order of magnitude; the intensity of their flux is very lower and nearly continuous in time. What is dangerous for human health is the accumulation of their effects at an interval of time of several months or a few years [1]. According to the measurements of the Radiation Assessment Detector (RAD) instrument on the Mars Science Laboratory (MSL) during the cruise to Mars, the average daily radiation dose is about $1.84 \mathrm{mSv}$; GCRs contributed $95 \%$ to the total dose during the journey [2]. Therefore, during the foreseen 500-day mission to and from Mars, the dose due to GCRs will far exceed the limitation recom- mended by the International Commission on Radiological Protection (ICRP) [3].

Radiation shielding is a major concern for future manned missions, especially outside the low Earth orbit [4-6]. Passive shielding is one of the radiation countermeasures under consideration as human operations are extended into deep space. However, completely shielding a spacecraft with passive shielding may be too costly due to the amount of mass required, especially when the energetic GCRs are considered $[7,8]$. The total mass necessary to conservatively protect humans on a 500-day Mars mission is estimated to be around 1280 metric tons, the equivalent of 32 heavy-lift launches [9]. For most of the particles and energies found in the GCR spectrum, the effectiveness of a material as a radiation shield generally increases with decreasing atomic number, and hydrogen being the best [10]. Hydrogenousrich materials have drawn great attention from researchers for reducing the required mass of space radiation shielding, and a variety of approaches related to such materials have been considered in the design of space components [11-15]. Among polymers used to make the composites, polyethylene has a large percentage of hydrogen nuclei, with a chemical composition of $\mathrm{C}_{2} \mathrm{H}_{4}$; it is the well-known 


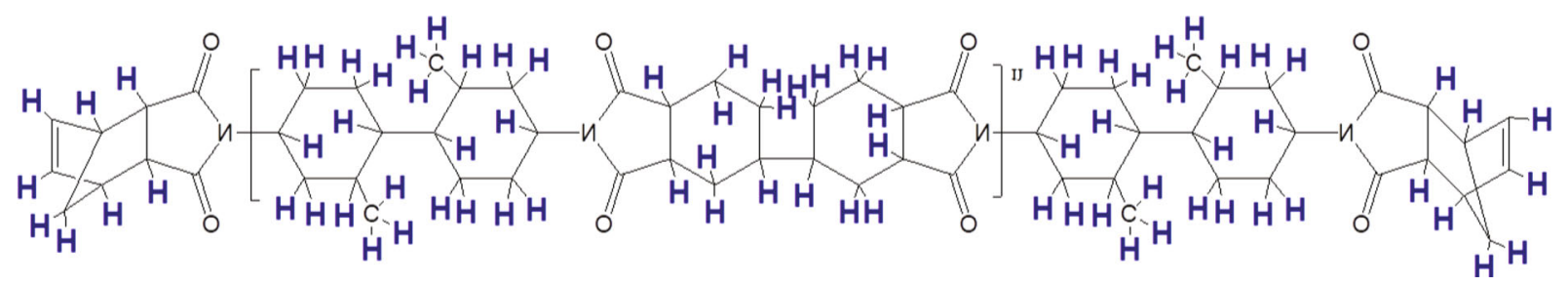

Figure 1: Molecular structure of resin matrix. The polymer material with high hydrogen content was synthesized through the design of resin molecular structure.

radiation shield material. Boron could play an important role, as the ${ }^{10} \mathrm{~B}$ isotope has a high cross-section useful to absorb neutrons $[16,17]$. Several hydrogenous composites with ${ }^{10} \mathrm{~B}$ were proposed as alternative space radiation shielding materials [18-21]. Due to its low melting point, polyethylene cannot be used alone in environments above $100^{\circ} \mathrm{C}$. Meanwhile, the ${ }^{10} \mathrm{~B}$ fillers used in these composites suffered from the lack of interfacial adhesion with the polyethylene matrix, leading to a limited improvement or even decay of physical and radiation shielding properties of the composites. Therefore, conventional composites are difficult to meet the application needs of radiation, temperature, and mechanics at the same time.

In this paper, two kinds of hydrogenous-rich composites with excellent mechanical properties are developed through compressing molding under high-temperature processing techniques for shielding space radiation. Additionally, beams of $80 \sim 400 \mathrm{MeV} / \mathrm{n}{ }^{12} \mathrm{C}$ of the Heavy Ion Research Facility in Lanzhou are used to test the shielding properties of composites. Finally, Monte Carlo simulation was used to assess the shielding performance of $\mathrm{PE}$ in real space radiation.

\section{Materials and Methods}

The basic process of composite fabrication is as follows. In the first step, the special resin with high hydrogencontaining was synthesized through the design of molecular structure; in the second step, the high-density polyethylene fiber was used as reinforcement to prepare high hydrogencontaining composites; in the third step, boron powder was used as an additive to optimize the shielding performance of the composites.

2.1. Preparation of High Hydrogen-Containing Resin. The polymer material with high hydrogen content was designed and synthesized through the design of resin molecular structure. The material also has excellent high- and lowtemperature cycle resistance. The molecular structure of the resin matrix is shown in Figure 1. Firstly, the resin solution with a reactive end-capping agent is prepared, which has the characteristics of low viscosity and high solid content. The viscosity of the resin is only $500 \mathrm{MPa} \cdot \mathrm{s}$, and there is no solvent released during curing.

Due to the high curing temperature of the resin system, a special curing agent and catalyst were added to the resin system to reduce the curing temperature to adapt to composite with high-density polyethylene (HDPE) fiber, as shown in
TABLE 1: Effect of curing agent content on curing time.

\begin{tabular}{lcc}
\hline Resin: curing agent & Catalyzer & $\begin{array}{c}\text { Curing time at room } \\
\text { temperature }(\mathrm{h})\end{array}$ \\
\hline $1: 0.61$ & -- & -- \\
$1: 0.46$ & 0.02 & $\approx 72$ \\
$1: 0.54$ & 0.02 & $\approx 72$ \\
$1: 0.61$ & 0.02 & $>96$ \\
$1: 0.69$ & 0.02 & $>96$ \\
\hline
\end{tabular}

TABLE 2: Glass transition temperature data of cured products.

\begin{tabular}{lcc}
\hline Resin $:$ curing agent $:$ catalyzer & Postcuring or not & $\operatorname{Tg}\left({ }^{\circ} \mathrm{C}\right)$ \\
\hline $1: 0.46: 0.02$ & No & 84.32 \\
$1: 0.54: 0.02$ & No & 96.46 \\
$1: 0.61: 0.02$ & No & 107.55 \\
$1: 0.69: 0.02$ & No & 123.41 \\
$1: 0.46: 0.02$ & Yes & 88.76 \\
$1: 0.54: 0.02$ & Yes & 103.74 \\
$1: 0.61: 0.02$ & Yes & 107.33 \\
$1: 0.69: 0.02$ & Yes & 130.57 \\
\hline
\end{tabular}

Table 1. The results show that when the mass ratio of resin, curing agent, and catalyst is $1: 0.46: 0.02$, the curing time at room temperature is about 72 hours. This ensures that there is enough sizing time while reducing the curing time.

At the same time, the influence of the mass ratio of resin, curing agent, and catalyst on the glass transition temperature $(\mathrm{Tg})$ of the cured resin was studied, as shown in Table 2. The results show that the $\mathrm{Tg}$ is the highest when the mass ratio of resin, curing agent, and catalyst is $1: 0.69: 0.02$ and after curing.

2.2. Preparation of Hydrogenous-Rich Composite. HDPE fiber was used as reinforcement, and the prepreg was prepared with the special resin obtained from the above research. The cured sheet with the designed size was directly prepared by hot pressing technology. The mass percent of HDPE fiber in the cured sheet was more than $60 \%$, and the mass percent of resin was less than $40 \%$. The resin, curing agent, and accelerator were mixed in the mass ratio of 1:0.69:0.02 and evenly coated on the polyethylene fiber. The coated cloth is cured in an oven at $60^{\circ} \mathrm{C}$ for 30 minutes so that the resin can be cured a little and the cloth can be easily removed. Fold the cloth repeatedly, wrap it with glass cloth and polyimide film, and then press the plate. The 


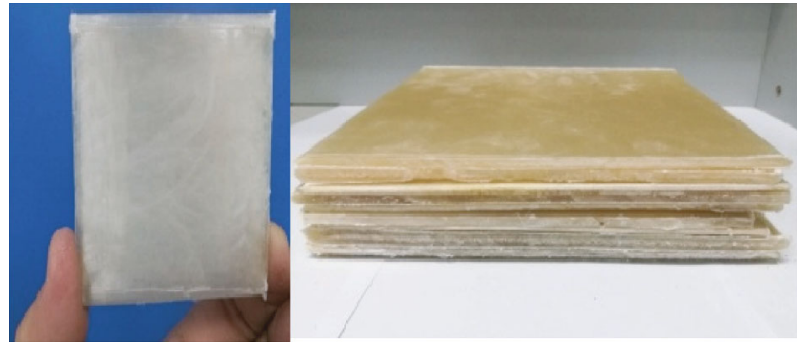

Figure 2: Pictures of PE plate. PE has a smooth surface, uniform texture, and milky color.

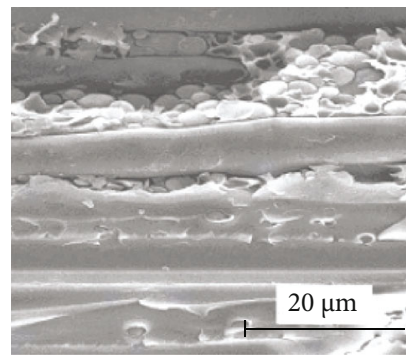

FIGURE 3: SEM analysis results of the composite after the interlaminar fracture test. Spherical particles can prevent the crack growth.

curing procedure is $110^{\circ} \mathrm{C}$ for 1 hour, $130^{\circ} \mathrm{C}$ for 2 hours, and $150^{\circ} \mathrm{C}$ for 1 hour to obtain the composite (name the material with $\mathrm{PE}$ ) with a smooth surface and uniform texture, as shown in Figure 2.

The content of hydrogen, carbon, nitrogen, and oxygen in the composite is $12.05 \%, 80.51 \%, 2.26 \%$, and $5.18 \%$, respectively. The composite has excellent mechanical strength; the flexural strength and flexural moduli are $179 \mathrm{MPa}$ and $9628 \mathrm{MPa}$, respectively. Figure 3 shows the scanning electron microscope (SEM) analysis results of the composite after the interlaminar fracture test. It can be seen from the figure that when the crack propagation, these spherical particles can play a good role in delaying or preventing the crack growth, absorb more energy, and achieve a better toughening effect.

\subsection{Preparation of Hydrogenous-Rich Composite with} Modified Boron Fillers. Due to the high neutron capture cross-section of boron, boron was added into the high hydrogen-containing resin to improve the shielding ability of secondary neutrons produced by cosmic ray bombardment materials. Different contents of boron were added to the resin solution to study its influence on the viscosity of the resin, as shown in Table 3. The results show that the higher the filler content, the higher the viscosity of the resin. When the boron filler is $20 \%$, the resin viscosity is suitable for fiber coating. If the viscosity continues to increase, it is not conducive to fiber coating.

The surface of the hydrogenous-rich composite (name the material with PE/B) modified with boron filler is smooth, and the texture is uniform, as shown in Figure 4. The flexural strength and flexural modulus of the composite are $140 \mathrm{MPa}$ and $15489 \mathrm{MPa}$, respectively.
TABLE 3: Influence of boron content on resin viscosity.

\begin{tabular}{lcc}
\hline Number & Filler content (\%) & Viscosity $(\mathrm{mPa} \cdot \mathrm{s})$ \\
\hline 1 & 0 & 500 \\
2 & 10 & 1400 \\
3 & 20 & 2400 \\
4 & 30 & 3600 \\
5 & 40 & 4900 \\
\hline
\end{tabular}
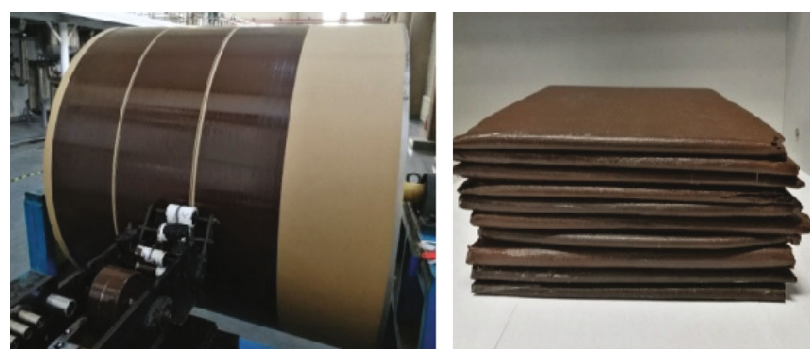

Figure 4: Pictures of PE/B plate. PE/B has a smooth surface, uniform texture, and dark purple color.

2.4. Specimen Preparation. The above two kinds of hydrogenous-rich composites were adopted for the irradiation test, as shown in Table 4 . The samples were prepared as $50 \mathrm{~mm} \times 50 \mathrm{~mm}$ size with different shielding thicknesses, which are related to the energy of particles.

2.5. Experimental Methods. Ideally, people want to expose different thickness material samples to the space radiation field and measure the dose in water versus shielding thickness. However, more controlled accelerators are generally used for experiments on the ground. In this study, beams of $80 \sim 400 \mathrm{MeV} / \mathrm{n}{ }^{12} \mathrm{C}$ of Heavy Ion Research Facility in Lanzhou (HIRFL) were used to measure the shielding properties of composite samples. This ion is representative of the heavy-ion component of the GCRs. The irradiation test layout is shown in Figure 5, a PTW Markus ionization chamber was used to monitor the number of particles. A PTW UNIDOS dosemeter was used to measure the energy depositions from charged particles, ion chamber, and silicon detector can be connected; a chamber library makes it possible to store calibration data. A Thermo Scientific FHT 762 Wendi-2 Wide-Energy Neutron Detector was used to measure the neutron dosimeter, which features high sensitivity and excellent energy (thermal to $5 \mathrm{GeV}$ ) and angular response provided by the WENDI-2 design originally developed at Los Alamos. The main equipment for testing material shielding property is shown in Figure 6.

2.6. Dose Calculation Methods. In radiological protection, the main interest is directed not to the absorbed dose at a point in the human body but to the absorbed dose averaged over a tissue or organ volume. The mean absorbed dose, $D_{T, R}$, in an organ or tissue $T$ due to radiation of type $R$ is the basic quantity for the definition of the protection quantity equivalent dose and effective dose used for describing exposures at low doses and dose rates where stochastic 
TABLE 4: Samples used for irradiation tests.

\begin{tabular}{|c|c|c|c|}
\hline \multicolumn{2}{|c|}{ PE $\left(\right.$ density $\left.0.94 \mathrm{~g} / \mathrm{cm}^{3}\right)$} & \multicolumn{2}{|c|}{$\mathrm{PE} / \mathrm{B}\left(\right.$ density $\left.1.08 \mathrm{~g} / \mathrm{cm}^{3}\right)$} \\
\hline Thickness (mm) & Thickness $\left(\mathrm{g} / \mathrm{cm}^{2}\right)$ & Thickness (mm) & Thickness $\left(\mathrm{g} / \mathrm{cm}^{2}\right)$ \\
\hline \multicolumn{4}{|l|}{$80 \mathrm{MeV} / \mathrm{n}^{12} \mathrm{C}$} \\
\hline 2 & 0.188 & 2 & 0.216 \\
\hline 4 & 0.376 & 4 & 0.432 \\
\hline 6 & 0.564 & 6 & 0.648 \\
\hline 8.2 & 0.771 & 8 & 0.864 \\
\hline 10.2 & 0.959 & 10 & 1.080 \\
\hline 12 & 1.128 & 11 & 1.188 \\
\hline 13 & 1.222 & 12 & 1.296 \\
\hline 14.4 & 1.354 & 14.5 & 1.566 \\
\hline 16.4 & 1.542 & 16.5 & 1.782 \\
\hline 18.4 & 1.730 & 18.5 & 1.998 \\
\hline 23.8 & 2.237 & 22 & 2.376 \\
\hline 27.8 & 2.613 & 26 & 2.808 \\
\hline 33.6 & 3.158 & 30 & 3.240 \\
\hline 40 & 3.760 & 39.6 & 4.277 \\
\hline \multirow[t]{2}{*}{58} & 5.452 & 49.6 & 5.357 \\
\hline & & 59.6 & 6.437 \\
\hline \multicolumn{4}{|l|}{$400 \mathrm{MeV} / \mathrm{n}{ }^{12} \mathrm{C}$} \\
\hline 28 & 2.632 & 35 & 3.780 \\
\hline 130 & 12.220 & 138 & 14.904 \\
\hline 202 & 18.988 & 238 & 25.704 \\
\hline 257 & 24.158 & 267 & 28.836 \\
\hline 268 & 25.192 & 288 & 31.104 \\
\hline 285 & 26.790 & 317 & 34.236 \\
\hline 312 & 29.328 & 500 & 54.000 \\
\hline 372 & 34.968 & 714 & 77.112 \\
\hline 576 & 54.144 & & \\
\hline
\end{tabular}

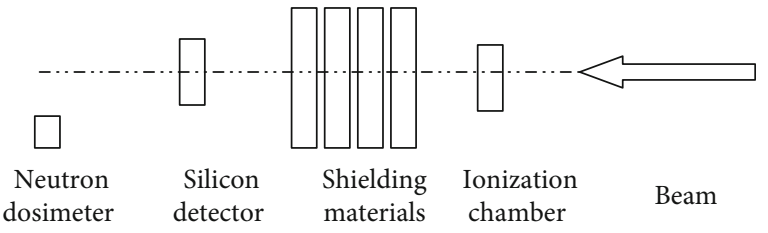

FIgURE 5: Irradiation test layout. The particles irradiate the material sample vertically from the left.

effects are dominant. In mixed radiation fields, the mean absorbed dose, $D_{T}$, in an organ or tissue $T$ is given by

$$
\mathrm{D}_{T}=\sum_{R} D_{T, R}
$$

For strongly penetrating radiation, however, the absorbed dose distribution within most organs may be sufficiently homogeneous, and thus, the mean absorbed dose is generally a suitable measure of the dose throughout the organ or tissue.

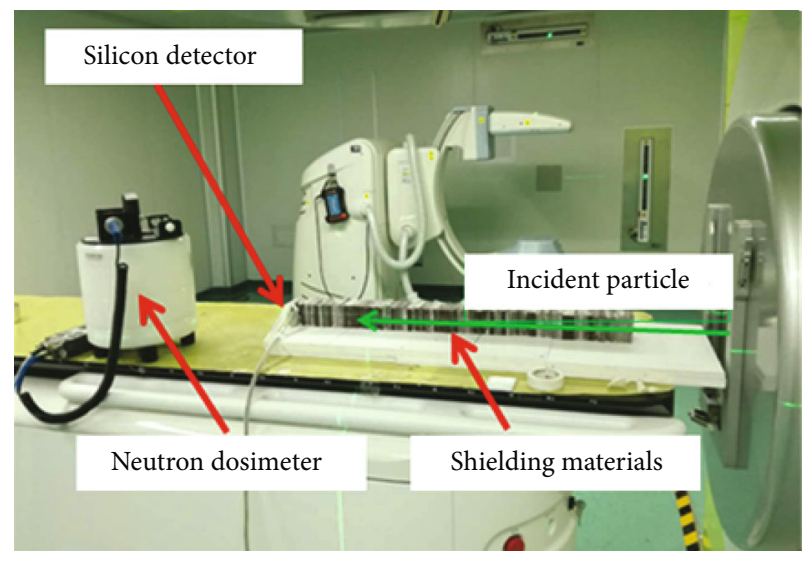

FIgURE 6: Equipment for irradiation test. The material samples are stacked on the sample table to obtain different shielding thickness combinations.

The protection quantity equivalent dose in an organ or tissue, $H_{T}$, is defined by

$$
H_{T}=\sum_{R} w_{R} D_{T, R}
$$


TABLE 5: Experimental results irradiated by $80 \mathrm{MeV} / \mathrm{n}{ }^{12} \mathrm{C}$ ions.

\begin{tabular}{|c|c|c|c|c|c|c|}
\hline Thickness (mm) & Thickness $\left(\mathrm{g} / \mathrm{cm}^{2}\right)$ & Counts & $\begin{array}{l}\text { Absorbed } \\
\text { dose }(\mathrm{Gy})\end{array}$ & $\begin{array}{c}\text { Neutron dose } \\
\text { equivalent }(\mu \mathrm{Sv})\end{array}$ & $\begin{array}{c}\text { Normalized }{ }^{12} \mathrm{C} \\
\text { dose equivalent }(\mu \mathrm{Sv})\end{array}$ & $\begin{array}{l}\text { Normalized neutron } \\
\text { dose equivalent }(\mu \mathrm{Sv})\end{array}$ \\
\hline \multicolumn{7}{|c|}{$P E\left(\right.$ density $\left.0.94 \mathrm{~g} / \mathrm{cm}^{3}\right)$} \\
\hline 2 & 0.188 & 40615 & 5.070 & 6.220 & $2.50 E+03$ & $1.53 E-04$ \\
\hline 4 & 0.376 & 40525 & 5.820 & 5.900 & $2.87 E+03$ & $1.46 E-04$ \\
\hline 6 & 0.564 & 39651 & 5.860 & 5.600 & $2.96 E+03$ & $1.41 E-04$ \\
\hline 8.2 & 0.771 & 39921 & 7.070 & 5.600 & $3.54 E+03$ & $1.40 E-04$ \\
\hline 10.2 & 0.959 & 40189 & 8.740 & 5.410 & $4.35 E+03$ & $1.35 E-04$ \\
\hline 12 & 1.128 & 39315 & 22.710 & 5.160 & $1.16 E+04$ & $1.31 E-04$ \\
\hline 13 & 1.222 & 44197 & 0.260 & 5.800 & $1.18 E+02$ & $1.31 E-04$ \\
\hline 14.4 & 1.354 & 39354 & 0.180 & 5.030 & $9.15 E+01$ & $1.28 E-04$ \\
\hline 16.4 & 1.542 & 39257 & 0.110 & 5.120 & $5.60 E+01$ & $1.30 E-04$ \\
\hline 18.4 & 1.730 & 39383 & 0.090 & 4.960 & $4.57 E+01$ & $1.26 E-04$ \\
\hline 23.8 & 2.237 & 68850 & 0.060 & 8.210 & $1.74 E+01$ & $1.19 E-04$ \\
\hline 27.8 & 2.613 & 41030 & 0.020 & 4.740 & $9.75 E+00$ & $1.16 E-04$ \\
\hline 33.6 & 3.158 & 40262 & 0.021 & 4.424 & $1.05 E+01$ & $1.10 E-04$ \\
\hline 40 & 3.760 & 41441 & 0.010 & 4.274 & $4.83 E+00$ & $1.03 E-04$ \\
\hline 58 & 5.452 & 41770 & 0.002 & 3.899 & $9.58 E-01$ & $9.33 E-05$ \\
\hline \multicolumn{7}{|c|}{$P E / B\left(\right.$ density $\left.1.08 \mathrm{~g} / \mathrm{cm}^{3}\right)$} \\
\hline 2 & 0.216 & 39337 & 5.271 & 6.163 & $2.68 E+03$ & $1.57 E-04$ \\
\hline 4 & 0.432 & 40782 & 5.890 & 6.129 & $2.89 E+03$ & $1.50 E-04$ \\
\hline 6 & 0.648 & 40342 & 6.608 & 5.988 & $3.28 E+03$ & $1.48 E-04$ \\
\hline 8 & 0.864 & 42281 & 8.680 & 6.101 & $4.11 E+03$ & $1.44 E-04$ \\
\hline 10 & 1.080 & 42080 & 11.707 & 5.978 & $5.56 E+03$ & $1.42 E-04$ \\
\hline 11 & 1.188 & 38904 & 18.510 & 5.541 & $9.52 E+03$ & $1.42 E-04$ \\
\hline 12 & 1.296 & 40630 & 1.643 & 5.780 & $8.09 E+02$ & $1.42 E-04$ \\
\hline 14.5 & 1.566 & 40827 & 0.152 & 5.595 & $7.42 E+01$ & $1.37 E-04$ \\
\hline 16.5 & 1.782 & 39519 & 0.103 & 5.385 & $5.20 E+01$ & $1.36 E-04$ \\
\hline 18.5 & 1.998 & 40363 & 0.081 & 5.291 & $4.03 E+01$ & $1.31 E-04$ \\
\hline 22 & 2.376 & 44762 & 0.062 & 5.648 & $2.76 E+01$ & $1.26 E-04$ \\
\hline 26 & 2.808 & 43478 & 0.039 & 5.263 & $1.79 E+01$ & $1.21 E-04$ \\
\hline 30 & 3.240 & 41308 & 0.024 & 4.980 & $1.14 E+01$ & $1.21 E-04$ \\
\hline 39.6 & 4.277 & 42124 & 0.008 & 4.762 & $3.70 E+00$ & $1.13 E-04$ \\
\hline 49.6 & 5.357 & 44652 & 0.003 & 4.706 & $1.25 E+00$ & $1.05 E-04$ \\
\hline 59.6 & 6.437 & 42475 & 0.001 & 4.178 & $5.18 E-01$ & $9.84 E-05$ \\
\hline
\end{tabular}

where $w_{R}$ is the radiation weighting factor for radiation $R$ which considers the differences in the radiobiological effectiveness of different radiations and $D_{T, R}$ is the average absorbed dose in the volume of a specified organ or tissue, $T$, due to radiation of type $R$. Effective dose, $E$, is defined by

$$
E=\sum_{T} w_{T} H_{T}
$$

where $w_{T}$ is the tissue weighting factor for organ or tissue $T$ representing the relative contribution of that organ or tissue to the total health detriment resulting from uniform irradiation of the body at low doses and dose rates. The sum is performed over 14 organs and tissues of the human body considered individually in the definition of $E$. The SI unit of effective dose is $\mathrm{J} \mathrm{kg}^{-1}$, and its special name is sievert (Sv). In the calculation of effective dose, the equivalent dose $H_{T}$ is taken as the mean value averaged over the male and female organ or tissue:

$$
H_{T}=0.5\left(H_{T}^{M}+H_{T}^{F}\right)
$$


TABLe 6: Experimental results irradiated by $400 \mathrm{MeV} / \mathrm{n}{ }^{12} \mathrm{C}$ ions.

\begin{tabular}{|c|c|c|c|c|c|c|}
\hline Thickness (mm) & Thickness $\left(\mathrm{g} / \mathrm{cm}^{2}\right)$ & Counts & $\begin{array}{l}\text { Absorbed } \\
\text { dose (Gy) }\end{array}$ & $\begin{array}{c}\text { Neutron dose } \\
\text { equivalent }(\mu \mathrm{Sv})\end{array}$ & $\begin{array}{c}\text { Normalized }{ }^{12} \mathrm{C} \\
\text { dose equivalent }(\mu \mathrm{Sv})\end{array}$ & $\begin{array}{l}\text { Normalized neutron } \\
\text { dose equivalent }(\mu \mathrm{Sv})\end{array}$ \\
\hline \multicolumn{7}{|c|}{$P E\left(\right.$ density $\left.0.94 \mathrm{~g} / \mathrm{cm}^{3}\right)$} \\
\hline 28 & 2.632 & 200498 & 2.066 & 35.195 & $2.06 E+02$ & $1.76 E-04$ \\
\hline 130 & 12.220 & 200566 & 1.751 & 57.765 & $1.75 E+02$ & $2.88 E-04$ \\
\hline 202 & 18.988 & 200515 & 1.724 & 62.696 & $1.72 E+02$ & $3.13 E-04$ \\
\hline 257 & 24.158 & 200664 & 2.873 & 56.206 & $2.86 E+02$ & $2.80 E-04$ \\
\hline 268 & 25.192 & 200599 & 379.862 & 75.202 & $3.79 E+04$ & $3.75 E-04$ \\
\hline 285 & 26.790 & 200745 & 278.861 & 55.320 & $2.78 E+04$ & $2.76 E-04$ \\
\hline 312 & 29.328 & 200720 & 153.647 & 63.133 & $1.53 E+04$ & $3.15 E-04$ \\
\hline 372 & 34.968 & 200697 & 45.741 & 62.843 & $4.56 E+03$ & $3.13 E-04$ \\
\hline 576 & 54.144 & 200665 & 5.382 & 68.320 & $5.36 E+02$ & $3.40 E-04$ \\
\hline \multicolumn{7}{|c|}{$P E / B\left(\right.$ density $\left.1.08 \mathrm{~g} / \mathrm{cm}^{3}\right)$} \\
\hline 35 & 3.780 & 200868 & 1.809 & 36.007 & $1.80 E+02$ & $1.79 E-04$ \\
\hline 138 & 14.904 & 200644 & 1.539 & 59.633 & $1.53 E+02$ & $2.97 E-04$ \\
\hline 238 & 25.704 & 200782 & 3.858 & 52.742 & $3.84 E+02$ & $2.63 E-04$ \\
\hline 267 & 28.836 & 200562 & 236.037 & 56.461 & $2.35 E+04$ & $2.82 E-04$ \\
\hline 288 & 31.104 & 200720 & 142.587 & 62.706 & $1.42 E+04$ & $3.12 E-04$ \\
\hline 317 & 34.236 & 200701 & 70.553 & 63.148 & $7.03 E+03$ & $3.15 E-04$ \\
\hline 500 & 54.000 & 200570 & 8.077 & 70.770 & $8.05 E+02$ & $3.53 E-04$ \\
\hline 714 & 77.112 & 200681 & 0.000 & 60.555 & $0.00 E+00$ & $3.02 E-04$ \\
\hline
\end{tabular}

where $H_{T}^{M}$ and $H_{T}^{F}$ are specified in male and female bodies represented by male and female reference voxel phantoms.

\section{Results}

This study used $80 \sim 400 \mathrm{MeV} / \mathrm{n}{ }^{12} \mathrm{C}$ ions to represent the complex GCR radiation field. The doses in the thin silicon detector and neutron dosimeter downstream of the target materials have been used to estimate the shieldinginduced change in the dose per particle. Detailed experimental results irradiated by ${ }^{12} \mathrm{C}$ ions with different energy are shown in Tables 5 and 6 . After considering the quality factor $(Q=20)$ of the ${ }^{12} \mathrm{C}$ particle given by ICRP [3], the detected absorbed dose is converted into dose equivalent. Meanwhile, the experimental results were normalized according to the number of irradiated particles.

After high-energy particles are shielded by materials, the radiation dose mainly comes from ${ }^{12} \mathrm{C}$ particles and secondary neutrons. Figure 7 shows the normalized ionization dose equivalent irradiated by the 80 and $400 \mathrm{MeV} / \mathrm{n}{ }^{12} \mathrm{C}$ ions with different shielding thicknesses. Figure 8 shows the normalized neutron dose equivalent irradiated by the 80 and $400 \mathrm{MeV} / \mathrm{n}{ }^{12} \mathrm{C}$ ions with different shielding thicknesses. It can be seen from Figure 7 that the shielding performance of $\mathrm{PE}$ is better than $\mathrm{PE} / \mathrm{B}$ for 80 and $400 \mathrm{MeV} / \mathrm{n}{ }^{12} \mathrm{C}$ particles. The main reason is that the content of hydrogen decreases with the increase of $B$ content. It can be seen from Figure 8 that PE/B has a better shielding effect than $\mathrm{PE}$ for $400 \mathrm{MeV} / \mathrm{n}{ }^{12} \mathrm{C}$ particles. On the contrary, PE has a better

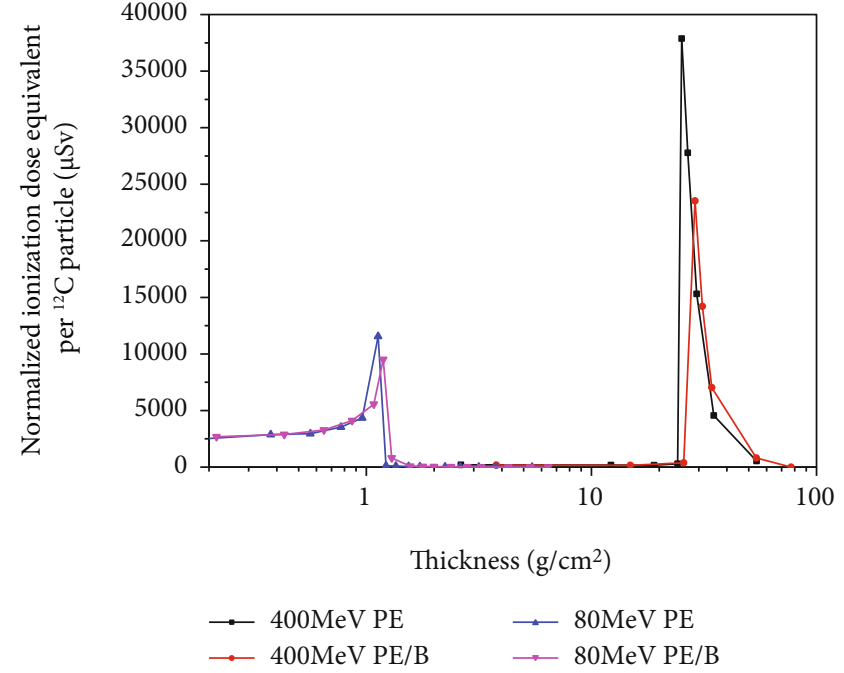

FIgURE 7: The normalized ionization dose equivalent irradiated by ${ }^{12} \mathrm{C}$ ions. Purple and blue represent $80 \mathrm{MeV} / \mathrm{n}{ }^{12} \mathrm{C}$ irradiation results. Red and black represent $400 \mathrm{MeV} / \mathrm{n}^{12} \mathrm{C}$ irradiation results.

shielding effect than $\mathrm{PE} / \mathrm{B}$ for $80 \mathrm{MeV} / \mathrm{n}{ }^{12} \mathrm{C}$ particles. The main reason is that the secondary neutron yield increases with the increase of ${ }^{12} \mathrm{C}$ particle energy and the thickness of shielding material. After that, ${ }^{10} \mathrm{~B}$ with high neutron absorption cross-section can reduce the neutron radiation dose. However, because the ${ }^{12} \mathrm{C}$ dose equivalent is much greater than neutron dose equivalent, the total shielding 


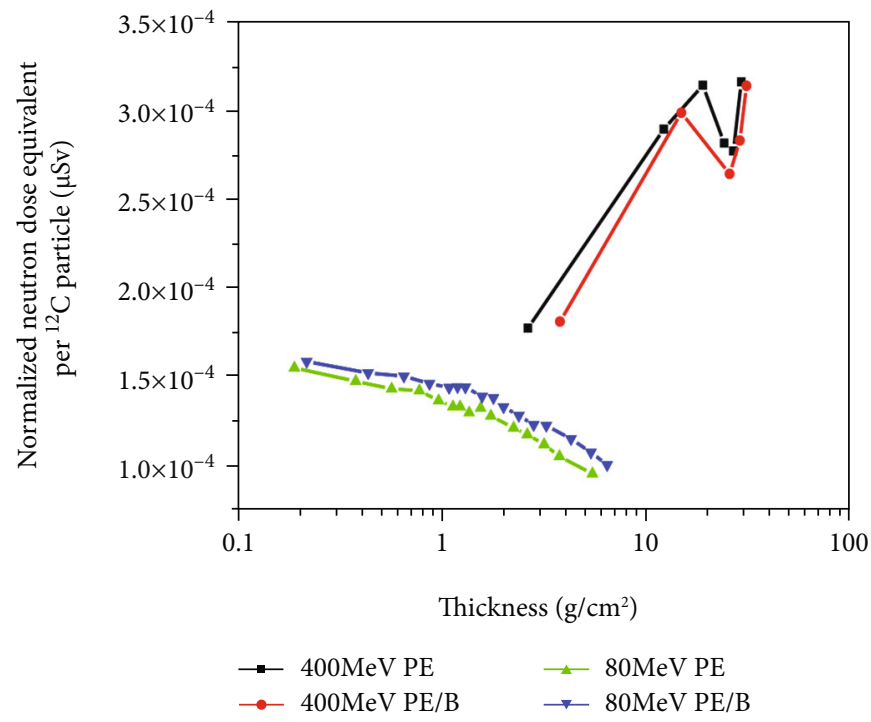

FIGURE 8: The normalized neutron dose equivalent irradiated by ${ }^{12} \mathrm{C}$ ions. Green and blue represent $80 \mathrm{MeV} / \mathrm{n}{ }^{12} \mathrm{C}$ irradiation results. Red and black represent $400 \mathrm{MeV} / \mathrm{n}^{12} \mathrm{C}$ irradiation results.

performance of $\mathrm{PE}$ is better than that of $\mathrm{PE} / \mathrm{B}$ for 80 $400 \mathrm{MeV} / \mathrm{n}{ }^{12} \mathrm{C}$ particles.

\section{Simulation with Real Space Radiation}

One of the main disadvantages of the ground accelerator test is that it can only use single energy fixed $Z$ heavy-ion beam. Although the results of these experiments are valid for specific ions, they rarely mention the kinds of residual particles that make up the GCR spectrum. To assess the shielding effectiveness of a given space radiation shielding material, one could simulate the radiation dose in target as a function of shielding Thickness using Monte Carlo radiation transport codes, such as Geant4 and FLUKA. For the simulation of space radiation interactions with shielding materials, we need to consider the following conditions: (1) the spectra of the primary radiation components in free space; (2) accurate information on the elemental composition, density, and geometry of shielding material; (3) the physical processes describe the interactions of the particles with the material nuclei and atoms. All these simulation aspects have been realized by the implementation of a full $3 \mathrm{D}$ model of the shielding material using the Geant4 simulation toolkit with proper distribution of the primary particles and considering suitable interaction processes in Geant4 [22, 23].

4.1. The Spectra of Primary Space Radiation. GCRs and SPEs are the main external radiation source impinging on shielding materials in free space. GCRs are primarily composed of protons $(\mathrm{H} \sim 89 \%)$, alpha particles $(\mathrm{He} 10 \%)$, and other heavier nuclei $(\sim 1 \%)$. The CREME96 model is used in the current analysis to calculate the GCR flux in deep space. The CREME96 model provides the GCR energy spectrum from 1 to $10^{5} \mathrm{MeV} / \mathrm{n}$ for elements with $Z=1$ through $Z=$ 92. This study only takes into account elements with $Z=1$ through $Z=28$, since the resulting equivalent dose for elements with $Z$ greater than 28 provides a negligible contribu-

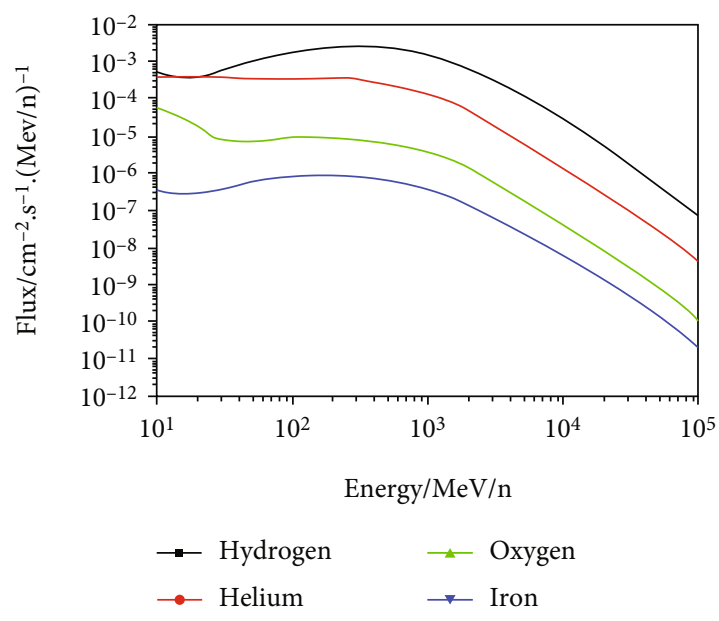

FIGURE 9: GCR spectra of four galactic cosmic radiation particles. Black, red, green, and blue represent the energy spectra of hydrogen, helium, oxygen, and iron particles in cosmic rays, respectively.

tion to the total equivalent dose $[3,24]$. The GCR spectra used in this analysis are corresponding to the 1977 solar minimum; flux distributions in energy for hydrogen, helium, oxygen, and iron are shown in Figure 9.

SPEs are mainly composed of protons from coronal mass ejections, which are unpredictable. Figure 10 shows the energy spectra of several larger proton events in history. In this work, the energy spectra of SPE in September 1989 were used [3].

4.2. Geometry and Composition of Materials. Early phase spacesuit design studies often consider simplified spherical/ slab shielding to quickly evaluate configuration options. Such studies may evaluate exposures versus spherical shield thickness curves for various candidate shielding materials, thereby allowing preliminary mass requirements and 


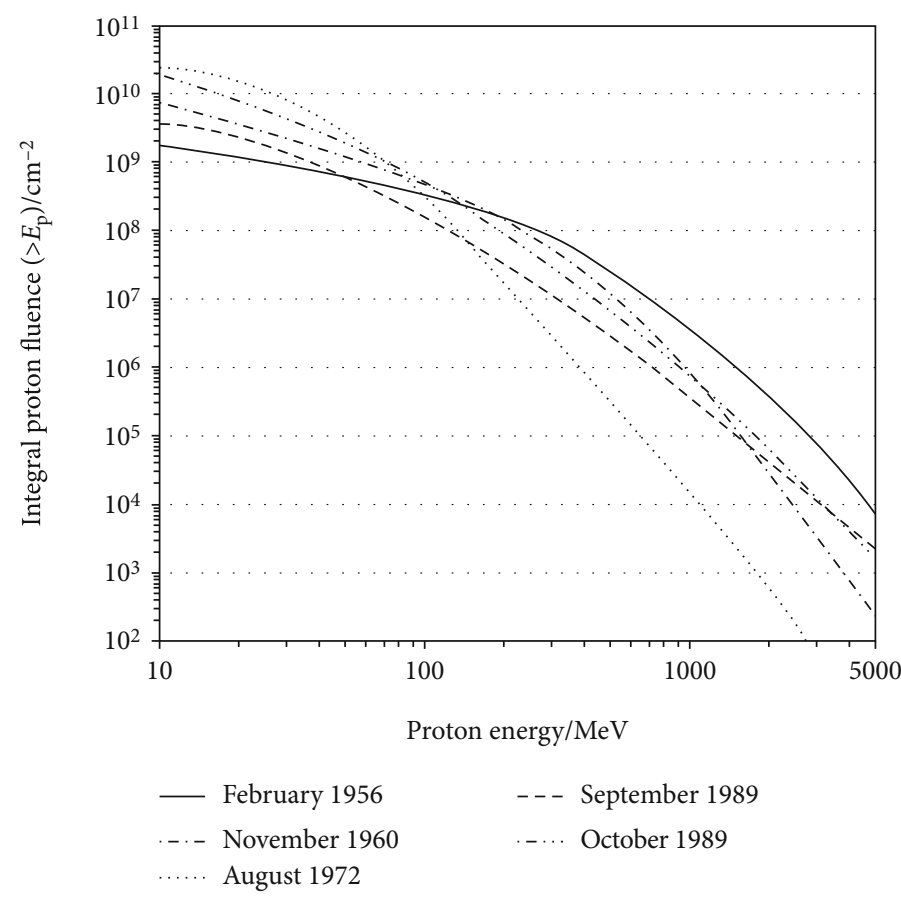

FigURE 10: SPE spectra of several larger proton events in history. Energy spectrum of solar proton events in 1956, 1960, 1972 , and 1989.

radiation constraints to be balanced against additional mission parameters. For one-dimensional (1D) transport calculations, isotropic irradiation of spherical geometry with a detector located at the center of the sphere is equivalent to uniformly directed irradiation (normal incidence) of slab geometry with a detector placed behind the slab. To improve the computational efficiency, a slab geometry model was used in our simulation. The advantage of this geometry is that all particles crossing between the upstream and downstream slabs are scored in dose, thereby improving convergence rates and overall computational efficiency. Geometric modeling is established considering the real working scene of astronauts. When astronauts are in extravehicular activities (EVA), space radiation acts directly on the shielding materials and finally hits on the human body, as shown in Figure 11. In the model, water is used to represent human tissue; the energy spectra of various particles after shielding materials can be calculated.

In this paper, the shielding properties of new hydrogenous-rich composites and traditional aluminum against actual space radiation are compared and studied. The main technical parameters of shielding materials are given in Table 7.

4.3. Physical Interaction Models. A Monte Carlo toolkit Geant 4 is used to simulate the interaction of high-energy particles with the shielding material. We used the reference physics list: QGSP physics list with the binary cascade model QGSP_BIC_HP (Geant4, 2019b), provided in Geant4 which is recommended for cosmic-ray applications and optimally covers the interaction processes relevant here. This physics list utilizes the quark-gluon string model for high-energy

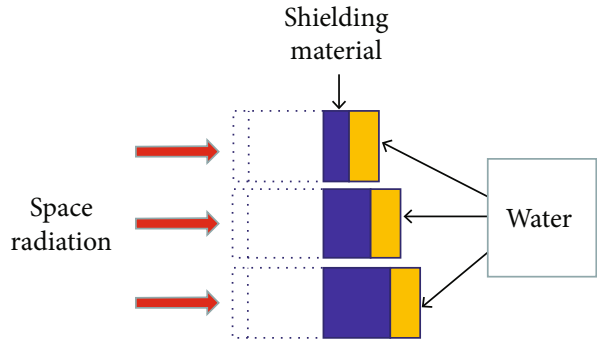

FIgURE 11: Slab geometry exposed to space radiation in EVA scene. Purple represents shielding material, and yellow represents water for recording energy deposition.

TABLE 7: Information of shielding materials.

\begin{tabular}{lccc}
\hline Number & Material & Content & Density $\left(\mathrm{g} / \mathrm{cm}^{3}\right)$ \\
\hline \multirow{3}{*}{1} & & H: $12.05 \%$ & \\
& PE & C: $80.51 \%$ & 0.940 \\
& & N: $2.26 \%$ & \\
2 & Oluminum & Al: $100 \%$ & $2.18 \%$ \\
\hline
\end{tabular}

interactions with nucleons, pions, and nuclei down to $\sim 20 \mathrm{GeV}$. Energies between $10 \mathrm{GeV}$ and $20 \mathrm{GeV}$ are handled by the FRITIOF precompound model, and the Bertini cascade model is used for interactions below $10 \mathrm{GeV}$. Postinteraction nuclear deexcitation is handled by the compound model. This physics list includes the high precision neutron interaction model to handle the elastic and inelastic scattering, capture, and fission more accurately from $20 \mathrm{MeV}$ down to thermal neutrons. To handle the electromagnetic part of 


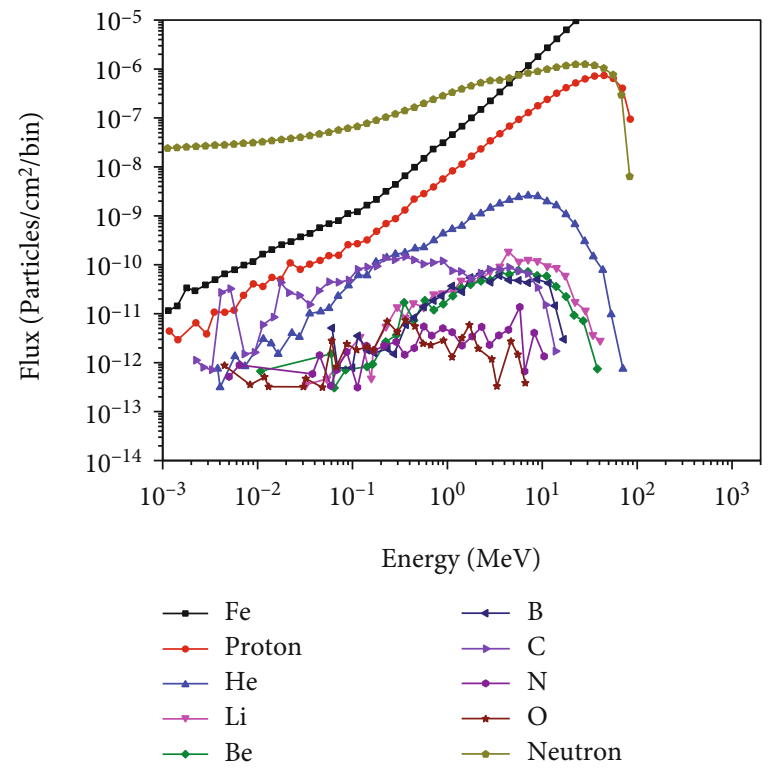

(a)

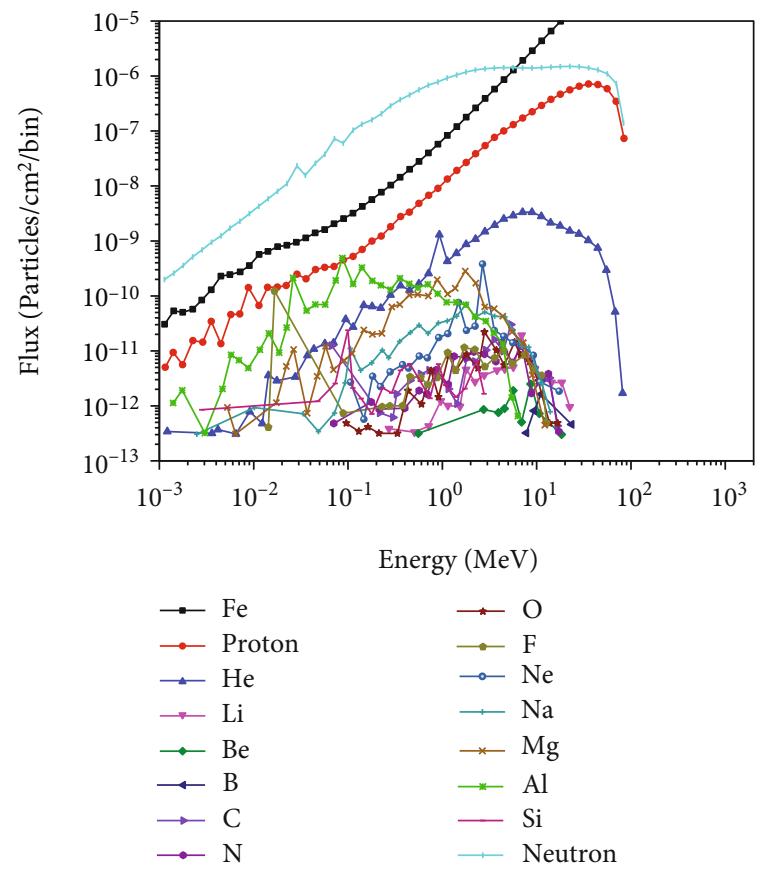

(b)

FIGURE 12: The energy spectra of various particles generated by $400 \mathrm{MeV} / \mathrm{n}$ Fe irradiated: (a) PE with $2 \mathrm{~g} / \mathrm{cm}^{2}$ thickness; (b) Al with $2 \mathrm{~g} / \mathrm{cm}^{2}$ thickness. Different colors are used to represent different kinds of secondary particles.

this model, the "standard" Geant4 electromagnetic physics which is valid from $100 \mathrm{eV}$ to $100 \mathrm{TeV}$ is used. More information about the chosen physics list can be found on the Geant4 website.

4.4. Simulation Results and Discussion. Geant4 simulation can supply the energy spectra of various particles generated by GCRs and SPEs irradiated shielding materials. Figure 12 shows the energy spectra of different particles generated by $400 \mathrm{MeV} / \mathrm{n}$ Fe irradiated.

The energy spectra of various particles obtained by Geant4 simulation can be used to assess organ and tissue doses directly. ICRP Publication 123 shows conversion coefficients (particle fluence to mean absorbed doses in organs or tissues) and mean quality factors for protons, charged pions, neutrons, alpha particles, and heavy ions $(2<Z \leq 28$ ), and particle energies up to $100 \mathrm{GeV} / \mathrm{n}$ [3].

According to the dose calculation methods given in Section 2.6, effective dose versus shielding thickness curves for various candidate shielding materials can be obtained. Figure 13 shows the effective doses from GCRs and SPEs after shielding with different thickness shielding materials.

As can be seen from Figure 13, PE has a better shielding performance than aluminum for space radiation. Moreover, $\mathrm{PE}$ is more effective for GCRs than SPEs. The main reason is that GCR particles have higher energy, which can produce more secondary radiation. The mass required for $\mathrm{PE}$ to achieve the same radiation protection capability as aluminum will be significantly reduced. When the shielding thickness is larger than $10 \mathrm{~g} / \mathrm{cm}^{2}$, the mass needed for shielding can be reduced by more than $77 \%$ and $33 \%$ for GCRs and SPEs, respectively.

\section{Discussion}

Passive shielding is one of the radiation countermeasures under consideration as human operations are extended into deep space. Hydrogenous materials such as polyethylene have been shown to be effective in shielding against GCRs and SPEs. National Aeronautics and Space Administration (NASA) materials scientists are developing new composites that have both high hydrogen content and sufficient tensile strength to serve as structural members in spacecraft [25]. It was reported that ${ }^{10} \mathrm{~B}$-containing matters such as boron carbide $\left(\mathrm{B}_{4} \mathrm{C}\right)$ and boron nitride $(\mathrm{BN})$ are excellent neutron absorbers by virtue of their huge thermal neutron absorbances [21]. HDPE/ $\mathrm{B}_{4} \mathrm{C}$ composites were fabricated via conventional polymer processing techniques, which have higher radiation shielding performance and better mechanical properties than HDPE [18]. The HDPE/BN composites were also reported for the radiation shielding application. However, the BN fillers used in these composites suffered from the lack of interfacial adhesion with the HDPE matrix, leading to a limited improvement or even decay of physical and radiation shielding properties of the $\mathrm{HDPE} / \mathrm{BN}$ composites [26]. Other polymers such as low-density PE (LDPE), epoxy, polystyrene, and polyimide were also considered as the nuclear protective matrices [15, 27-30]. These studies indicated that general composites are difficult to meet the environmental conditions of radiation, temperature, and mechanics in space at the same time.

In this study, two kinds of hydrogenous-rich composites are developed through compressing molding under hightemperature processing techniques for shielding space radiation. The composites have excellent mechanical strength, the 


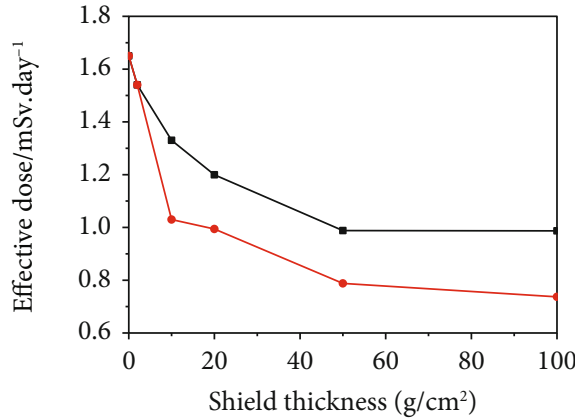

(a) GCRs

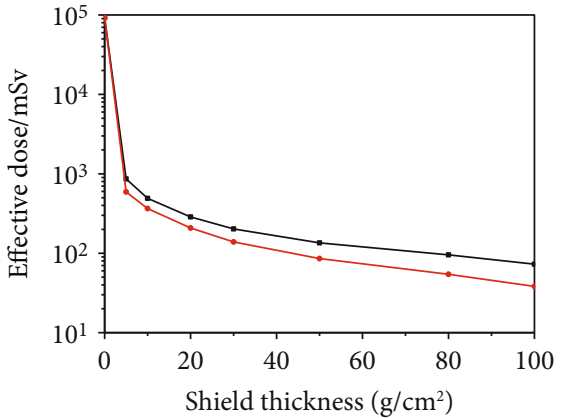

(b) SPEs

$\rightarrow$ Aluminum

$\rightarrow$ PE

FIGURE 13: Effective doses from space radiation: (a) GCRs; (b) SPEs. Black represents aluminum shielding capacity, and red represents PE shielding capacity.

flexural strength and flexural moduli are listed in Table 8. Moreover, the melting point of the composites is more than $150^{\circ} \mathrm{C}$.

Previous studies showed that ${ }^{10} \mathrm{~B}$ can reduce the neutron dose, which is significantly helpful to the shielding ability of composites [16, 17]. However, our experimental results show that adding ${ }^{10} \mathrm{~B}$ to the $\mathrm{PE}$ can improve the shielding ability for $400 \mathrm{MeV} / \mathrm{n}{ }^{12} \mathrm{C}$ particles, but it has no obvious effect on $80 \mathrm{MeV} / \mathrm{n}{ }^{12} \mathrm{C}$. The main reason is that the secondary neutron yield increases with the increase of ${ }^{12} \mathrm{C}$ particle energy and the thickness of shielding material. After that, ${ }^{10} \mathrm{~B}$ with high neutron absorption cross-section can reduce the neutron radiation dose. However, because the ${ }^{12} \mathrm{C}$ dose equivalent is much greater than neutron dose equivalent, the total shielding performance of $\mathrm{PE}$ is better than that of $\mathrm{PE} / \mathrm{B}$ for $80-400 \mathrm{MeV} / \mathrm{n}^{12} \mathrm{C}$ particles. In the past, only single particle type and single energy of ground accelerator were used to verify the shielding ability of composites [25, 27]. In this study, the Monte Carlo simulation method is used to evaluate the radiation shielding performance of composites in real GCRs and SPEs. Simulation results show that $\mathrm{PE}$ has significant advantage in space radiation shielding compared with traditional aluminum.

In this paper, a new hydrogen-rich composite was designed and developed, which can have excellent radiation shielding, temperature, and mechanical properties at the same time. The results show that the new composite has the potential to be used in manned spacecraft. In the future, more intensive research will be carried out on the release of harmful gases and temperature adaptability of the composite.

\section{Conclusions}

Two kinds of hydrogenous composites with excellent mechanical properties are developed through compressing molding under high-temperature processing techniques for shielding space radiation. The hydrogen content in $\mathrm{PE}$ and $\mathrm{PE} / \mathrm{B}$ is about $12.05 \%$ and $10.85 \%$, respectively. Beams of $80 \sim 400 \mathrm{MeV} / \mathrm{n}{ }^{12} \mathrm{C}$ of the Heavy Ion Research Facility in Lanzhou are used to measure the shielding properties of composites. Experimental results show that the shielding
TABLE 8: Mechanical properties of composites.

\begin{tabular}{lccc}
\hline Composite & $\begin{array}{c}\text { Density } \\
\left(\mathrm{g} / \mathrm{cm}^{3}\right)\end{array}$ & $\begin{array}{c}\text { Flexural strength } \\
(\mathrm{MPa})\end{array}$ & $\begin{array}{c}\text { Flexural modulus } \\
(\mathrm{MPa})\end{array}$ \\
\hline $\mathrm{PE}$ & 0.94 & 179 & 9628 \\
$\mathrm{PE} / \mathrm{B}$ & 1.08 & 140 & 15489 \\
\hline
\end{tabular}

performance of $\mathrm{PE}$ is better than $\mathrm{PE} / \mathrm{B}$ for 80 and $400 \mathrm{MeV} / \mathrm{n}{ }^{12} \mathrm{C}$ particles; the addition of boron has no obvious effect on improving the shielding performance. In order to make up for the disadvantages of the ground accelerator test, Monte Carlo simulation was used to assess the shielding performance of $\mathrm{PE}$ in real space radiation. The simulation results show that hydrogenous-rich composite has an obvious advantage in space radiation shielding compared with traditional aluminum. When the shielding thickness is larger than $10 \mathrm{~g} / \mathrm{cm}^{2}$, the mass needed for shielding can be reduced by more than $77 \%$ and $33 \%$ for GCRs and SPEs, respectively.

\section{Data Availability}

The raw data required to reproduce these findings cannot be shared at this time as the data also forms part of an ongoing study.

\section{Conflicts of Interest}

All authors declare no possible conflicts of interest.

\section{Authors' Contributions}

The authors were listed in order of contribution to this paper by providing literature research and summary, academic discussion, and insights.

\section{Acknowledgments}

This work was supported by the National Key R\&D Program of China (2020YFC2201300), Pandeng Program of National Space Science Center, Chinese Academy of Sciences, and 
Strategic Priority Research Program of Chinese Academy of Sciences (Grant No. XDA17010301).

\section{References}

[1] P. Spillantini, "Superconducting magnets and mission strategies for protection from ionizing radiation in interplanetary manned missions and interplanetary habitats," Acta Astronautica, vol. 68, no. 9-10, pp. 1430-1439, 2011.

[2] C. Zeitlin, D. M. Hassler, F. A. Cucinotta et al., "Measurements of energetic particle radiation in transit to mars on the mars science Laboratory," Science, vol. 340, no. 6136, pp. 10801084, 2013.

[3] G. Dietze, D. T. Bartlett, D. A. Cool et al., "ICRP Publication 123: Assessment of radiation exposure of astronauts in space," Ann ICRP, vol. 42, no. 4, pp. 1-339, 2013.

[4] J. Wilson, M. Clowdsley, F. Cucinotta, R. K. Tripathi, J. E. Nealy, and G. de Angelis, "Deep space environments for human exploration," Advances in Space Research, vol. 34, no. 6, pp. 1281-1287, 2004.

[5] M. Mahdavi and M. A. Amiri, "Space radiation effects on future quantum satellites," Aerospace Science and Technology, vol. 26, no. 1, pp. 72-75, 2013.

[6] M. Durante, "Space radiation protection: destination mars," Life Sciences in Space Research, vol. 1, pp. 2-9, 2014.

[7] B. Manning and R. Singleterry, "Radiation engineering analysis of shielding materials to assess their ability to protect astronauts in deep space from energetic particle radiation," Acta Astronautica, vol. 171, pp. 23-30, 2020.

[8] G. Horneck, R. Facius, M. Reichert et al., "HUMEX, a study on the survivability and adaptation of humans to long-duration exploratory missions, part II: missions to Mars," Advances in Space Research, vol. 38, no. 4, pp. 752-759, 2006.

[9] R. C. Singleterry, "Radiation engineering analysis of shielding materials to assess their ability to protect astronauts in deep space from energetic particle radiation," Acta Astronautica, vol. 91, pp. 49-54, 2013.

[10] C. Zeitlin, S. Guetersloh, L. Heilbronn, and J. Miller, "Shielding and fragmentation studies," Radiation Protection Dosimetry, vol. 116, p. 123, 2005.

[11] A. Emmanuel and J. Raghavan, "Influence of structure on radiation shielding effectiveness of graphite fiber reinforced polyethylene composite," Advances in Space Research, vol. 56, no. 7, pp. 1288-1296, 2015.

[12] M. R. Shavers, N. Zapp, R. E. Barber et al., "Implementation of ALARA radiation protection on the ISS through polyethylene shielding augmentation of the Service Module Crew Quarters," Advances in Space Research, vol. 34, no. 6, pp. 1333-1337, 2004.

[13] S. Laurenzi, G. de Zanet, and M. G. Santonicola, "Numerical investigation of radiation shielding properties of polyethylene- based nanocomposite materials in different space environments," Acta Astronautica, vol. 170, pp. 530-538, 2020.

[14] S. Kodaira, R. V. Tolochek, I. Ambrozova et al., "Verification of shielding effect by the water-filled materials for space radiation in the International Space Station using passive dosimeters," Advances in Space Research, vol. 53, no. 1, pp. 1-7, 2014.
[15] M. Naito, S. Kodaira, R. Ogawara et al., "Investigation of shielding material properties for effective space radiation protection," Life Sciences in Space Research, vol. 26, 2020.

[16] S. A. Thibeault, J. H. Kang, G. Sauti, C. Park, C. C. Fay, and G. C. King, "Nanomaterials for radiation shielding," Bulletin, vol. 40, no. 10, pp. 836-841, 2015.

[17] J. W. Shin, J. W. Lee, S. Yu et al., "Polyethylene/boron-containing composites for radiation shielding," Thermochimica Acta, vol. 585, no. 2, pp. 5-9, 2014.

[18] C. Harrison, E. Burgett, N. Hertel, and E. Grulke, "Polyethylene/boron composites for radiation shielding applications," AIP Conference Proceedings, vol. 969, pp. 484-491, 2008.

[19] S. A. Thibeault, C. C. Fay, S. E. Lowther et al., "Radiation shielding materials containing hydrogen, boron, and nitrogen: systematic computational and experimental study, Phase I," Tech. Rep. HQ-E-DAA-TN33851, NASA Langley Research Center, 2012.

[20] K. Okuno, "Neutron shielding material based on colemanite and epoxy resin," Radiation Protection Dosimetry, vol. 115, no. 1-4, pp. 258-261, 2005.

[21] Y. Huang, W. Zhang, L. Liang, J. Xu, and Z. Chen, "A "Sandwich" type of neutron shielding composite filled with boron carbide reinforced by carbon fiber," Chemical Engineer, vol. 220, pp. 143-150, 2013.

[22] "Introduction to Geant4," https://geant4-userdoc.web.cern.ch/ UsersGuides/IntroductionToGeant4/fo/IntroductionToGeant4 .pdf.

[23] T. Zhang, Y. B. Liu, B. Yang, H. X. Wu, and J. H. Gu, "Monte Carlo simulation of the exposure factor," Chinese Physics B, vol. 6, no. 18, pp. 113-118, 2009.

[24] J. A. Simpson, "Elemental and isotopic composition of the galactic cosmic rays," Annual Review of Nuclear and Particle Science, vol. 33, no. 1, pp. 323-382, 1983.

[25] S. Guetersloh, C. Zeitlin, L. Heilbronn et al., "Polyethylene as a radiation shielding standard in simulated cosmic-ray environments," Nuclear Instruments and Methods in Physics Research Section B: Beam Interactions with Materials and Atoms, vol. 252, no. 2, pp. 319-332, 2006.

[26] C. Harrison, S. Weaver, C. Bertelsen, E. Burgett, N. Hertel, and E. Grulke, "Polyethylene/boron nitride composites for space radiation shielding," Journal of Applied Polymer Science, vol. 109, no. 4, pp. 2529-2538, 2008.

[27] W. H. Zhong, G. Sui, S. Jana, and J. Miller, "Cosmic radiation shielding tests for UHMWPE fiber/nano-epoxy composites," Composites Science and Technology, vol. 69, no. 13, pp. 20932097, 2009.

[28] A. Canel, H. Korkut, and T. Korkut, "Improving neutron and gamma flexible shielding by adding medium-heavy metal powder to epoxy based composite materials," Radiation Physics and Chemistry, vol. 158, 2019.

[29] S. Winroth, C. Scott, and H. Ishida, "Structure and performance of benzoxazine composites for space radiation shielding," Molecules, vol. 25, p. 4346, 2020.

[30] F. Cataldo and M. Prata, "New composites for neutron radiation shielding," Journal of Radioanalytical \& Nuclear Chemistry, vol. 320, no. 3, pp. 831-839, 2019. 